\title{
The effectiveness of group cognitive behavioral therapy on continence: in addicts who reoffered to Tehran centers residence of addiction treatment
}

\author{
Zeynab Akbari ${ }^{1}$ \\ 1-MA of general Psychology, Allame Tabatabaei University .Tehran, Iran (Corresponding Author). ORCID: 0000- \\ 0003-2676-671X E-mail:zakbarisardehlaghi@gmail.com
}

Received: 28/01/2019

Accepted: 27/04/2019

\begin{abstract}
Introduction: One of the most important strategies for treatment and preventing recurrence of addiction is group cognitive behavioral psychotherapy.

Aim: The purpose of this study was assess the effectiveness of group cognitive behavioral therapy on continence in addicts Who recruited to Tehran centers Residence of Addiction Treatment.

Method: This was a semi experimental study using pre -test and post- test with control Group and follow-up. In order to conduct the experiment, among all addiction treatment centers in Tehran, the sound of kindness center was selected purposefully and twenty addicts who reoffered to this center were selected and assigned in two group randomly: experimental group $(\mathrm{n}=10)$ and control group $(n=10)$. All the participants were evaluated via the Continence questionnaire. Group cognitive behavioral therapy was performed in 8 sessions for experimental group and control group did not receive any treatment. The statistical method of MANOVA was used to analyze the data.
\end{abstract}

Results: Data analyze revealed that average of scores post-test and follow-test continence increased in experimental group and did not change in control group. This increase in experimental group in the post-test and follow-test was meaningful from statistically vision. $(\mathrm{p}<0.5)$.

Conclusion: conclusions demonstrated the effectiveness of group cognitive behavioral therapy on continence in addicts Who Reoffered to Tehran centers Residence of Addiction Treatment.

Keywords: Group cognitive- behavioral therapy, Continence, Addiction

How to cite this article : Akbari Z. The Effectiveness of Group Cognitive Behavioral Therapy on Continence: in Addicts Who Reoffered to Tehran centers Residence of Addiction Treatment. Shenakht Journal of Psychology and Psychiatry. 2019; 6 (2): 74-85. URL :http://shenakht.muk.ac.ir/article-1-490-fa.pdf 


\title{
اثربخشى تروه درمانى شناختى -رفتارى بر خويشتن دارى سوءمصرف كنندكان مواد مخدرِ مراجعه كننده به مراكز اقامتى ترك اعتياد (كميهاى) شهر تهران
}

\author{
زينب اكبرى'
}

ا. كارشناسى ارشد روان شناسى عمومى، دانشكاه علامه طباطبائى، تهران، ايران (مولف مسئول). ايميل: zakbarisardehlaghi@ gmail.com

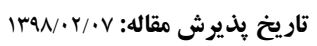

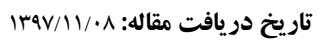

جكيده

مقدمه: يكى از مهم ترين راهكارهاى بيشخيرى و درمان اعتياد گروه درمانى شناختى رفتارى است.

هدف: هدف از اين تحقيق بررسى اثربخشى گروه درمانى شناختى- رفتارى بر خويشتن دارى سوءمصرف كنندگان مواد

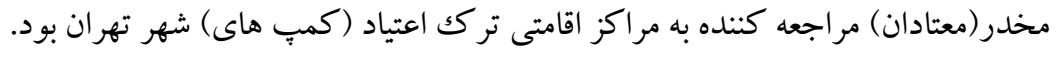

روش: اين تحقيق، يكك يُزوهش شبه آزمايشى با بيش آزمون، بس آزمون و بيخيرى همراه با گروه كنترل بود. براى اجراى اين

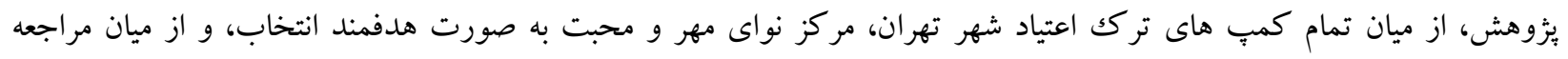

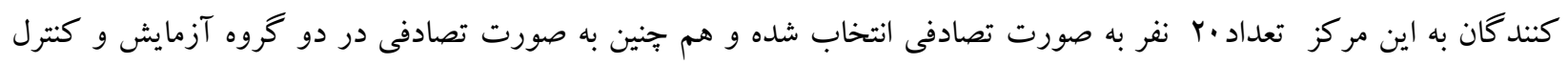

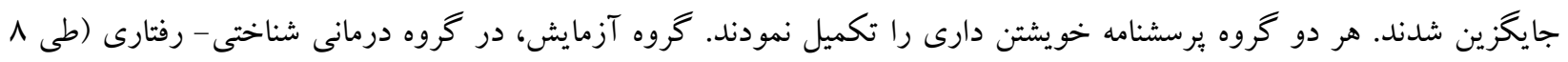

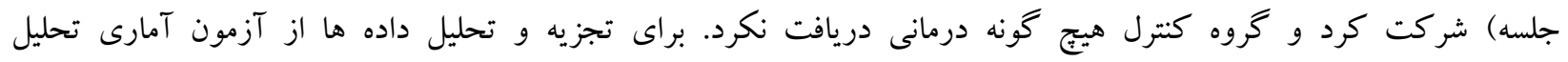
كوواريانس) (MANOVA) استفاده شد.

يافتهها: تجزيه و تحليل داده ها نشان داد كه ميانگين نمرات بـ آزمون و بيخيرى در گروه آزمايش افزايش يافت، در حالى كه

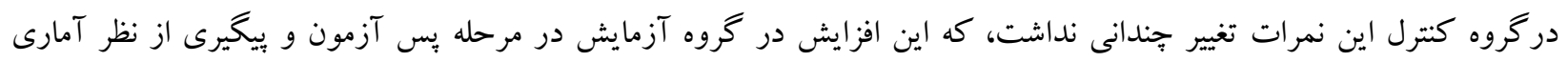
معنادار بود) (p)

نتيجه كيرى: با توجه به يافته ها مى توان گفت گروه درمانى شناختى - رفتارى بر خويشتن دارى سوءصرف كنند كان مواد مخدر موثر است. كليدوازه ها: خروه درمانى شناختى - رفتارى، خويشتن دارى، اعتياد 
خويشتن دارى بيشترى دارند، در همه حوزه ها موفق تر از

افرادى هستند كه تكانشى و بدون خودمهارگرى عمل

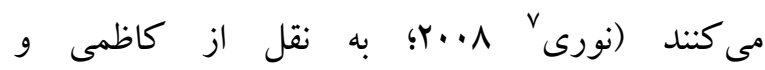
همكاران؛، (1) (Y). خويشتن دارى مستلزم مديريت و مهار احساسات است و افراد خويشتن دار از ثبات هيجانى بيشترى برخوردار خواهند بود و اين امر كارايى آنان را

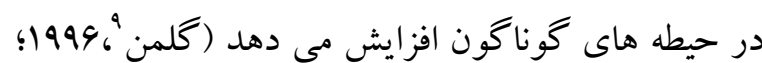

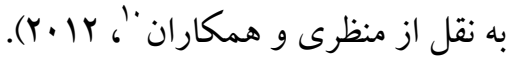

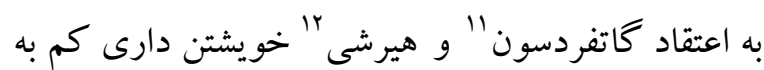
دليل تربيت اجتماعى ناقص و غيرموثر بديد آمده است. اراده، اعتماد به نفس و رشد عاطفى، عوامل عاطفى موثر

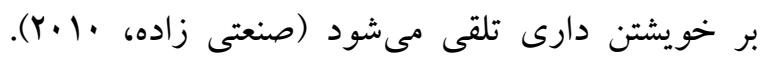

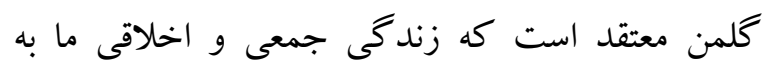
خويشتن دارى، غمخوارى و مهارت هاى مربوط به هوش الم عاطفى منوط است. در حيطهى اعتياد و سوء مصرف مواد، محققان بر نياز به مدلى كه از آسيب هاى جدى اعتياد و بيامدهاى آن يشخيرى كند، تاكيد كرده اند. بديهى است اين مدل بايد جند وجهى بوده و ابعاد فيزيكى، روان شناختى، روابط اجتماعى و محيطى را مدنظر قرار دهد (برو گلى و

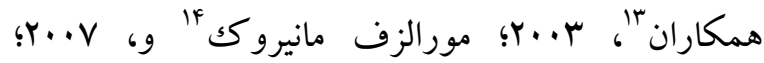

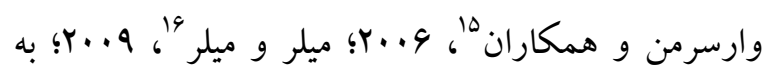

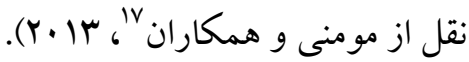

${ }^{7}$. Noori

${ }^{8}$.Kazemi, Mahdi nrzhad, Jamali

9 . Golman

${ }^{10}$.Manzari, Rajai pour, Abedi

11 .Gotferdson

${ }^{12}$.Hireshi

${ }^{13}$. Brogly, Mercier, Braneau, Palepu \&Franco

${ }^{14}$. Morales-Manrique

15 .Varsserman, Sorensen, Delucchi, Masson \& Hall

${ }^{16}$.Miller

${ }^{17}$. Momeni, Moshtagh, Poor shahbaz
بدون ترديد، مقابله با معضل اعتياد و ابعاد مختلف اين

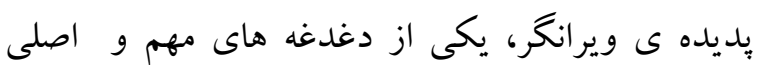

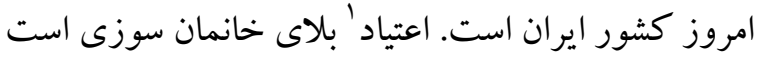
كه تبعات آن ساير افراد جامعه را تهديد ميكند. اين بديده، يكى از ييجيده ترين و بغرنج ترين آسيب هاى

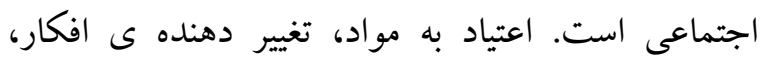
هيجان و رفتار و يكى از بارزترين آسيبهاى روانى -

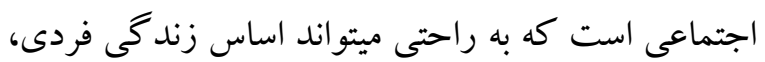
خانوادگى، اجتماعى و فرهنگى يكى كشور را از بين ببرد

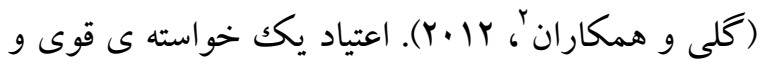
هميشگى است كه كنترل را به طور قابل توجهى كاهش ميدهد و منجر به آسيب قابل توجه مىشود (والترو بيكارد"، 199V). سوء مصرف مواد از جمله رفتارهايى است كه كاملا تحت كنترل اراده ى فرد نبوده و افراد در آن با عامل كنترل مواجه هستند. زيرا در اين رفتار عوامل داخلى و خارجى متعددى مى تو انند موثر واقع شوند، لذا وجود سازه اى مانند خويشتن دارى كه از جمله سازههاى كار آمد در كنترل رفتار است، مىتواند به فرد در مديريت رفتار خود كمكك كند. خويشتن دارى محالت روحى و صفتى است كه باعث توانايى شخص و برترى فرد بر ديخران مى شود به طورى كه بر اثر اين حس به آن جه در زندكى مطلوب و و

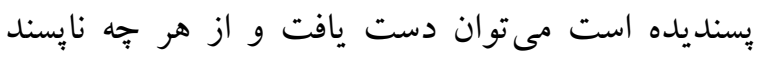

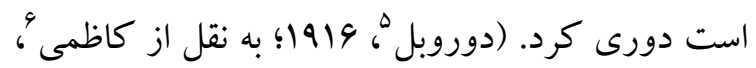

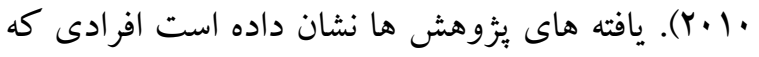

\footnotetext{
1 . addiction

2 . Goli, Emami pour, Javanmard

3. Valter \& Pickard

${ }^{4}$.continence

5 .Dorbell

${ }^{6}$. Kazemi
} 


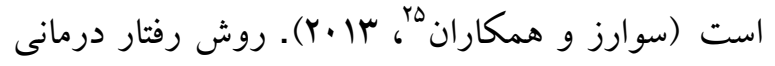

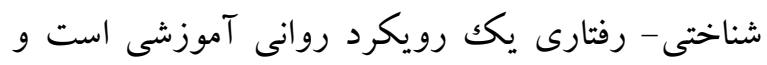
يكك روش روان درمانى كوتاه مدت محسوب مى شود كه حداقل در هشت جلسه و حداكثر در بيست جلسه ى إنه دقيقه اى اين خدمات به درمانجويان ارائه ميشود

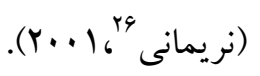
نيك ${ }^{T V}$ معتادان مرد درمان شناختى -رفتارى را موثر ززارش كرده است. او نتيجه كيرى مى كند كه يافته ها به طور آشكار نشان مى دهند كه رويكرد شناختى رفتارى براى حل مشكلات اعتياد و درماندكى مفيد بوده است و مى توان

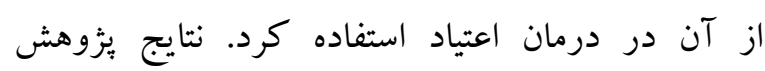
فيرو (Y) (Y. نيز در مورد ميزان بهبودى اعتياد به مواد مخدر نشان داد كه از بين انواع مدلهاى مختلف درمان، درمان شناختى رفتارى از بيشترين ميزان تاثير برخوردار

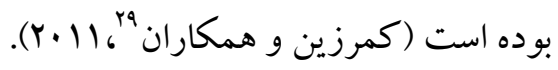

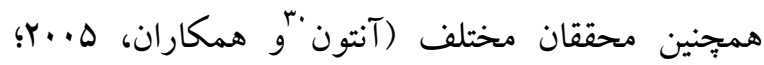

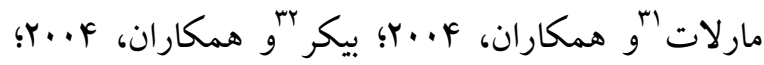

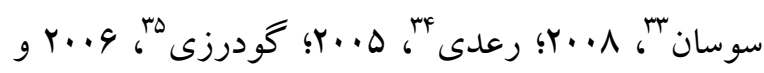

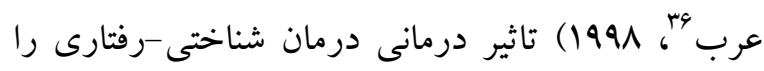
در درمان انواع اعتياد مورد تاكيد قرار داده اند (تاجرى و

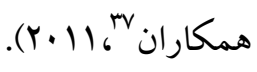

\footnotetext{
25. Suarze, Karmago \&Pizinato

${ }^{26}$. Narimani

${ }^{27}$.Nick

${ }^{28}$.Fierro

${ }^{29}$.Kamarzin, Zarea, Brokimillan

${ }^{30}$. Anton

${ }^{31}$. Marlat

${ }^{32}$. Biker

${ }^{33}$. Sosan

${ }^{34}$.Readi

${ }^{35}$.Gudarzi

${ }^{36}$.Arab

${ }^{37}$.Tajeri, Ahadi, Jomehri
}

يكى از الكوهاى مداخله ایى روان شناختى برجسته در

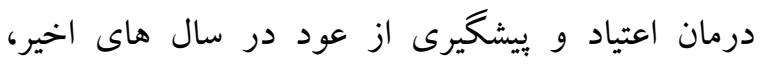
الكوى درمانى شناختى-رفتارى است، كه بر كمكك به بيمار براى كسب مهارت هاى مقابله اى لازم به منظور مديريت موقعيت هاى خطر ساز و درمان اختلالات روان شناختى همراه ، تمركز دارد. در مورد تاثير و كارايى شناختى -رفتارى در درمان اختلال هاى مصرف مواد، ارزشيابى هاى زيادى صورت گ خرفته كه نتايج آن ها نشان دهندهى كارايى اين رويكرد درمانى است (ميلر و

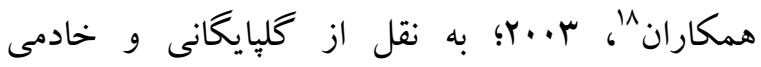

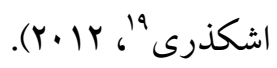
امروزه گ گروه درمانى ‘به عنوان درمان انتخابى اختلالات وابستخى به مواد داراى توان بالقوه براى حمايت و ورون مواجهاه ى بيمار با اختلال و به جالش كشيدن بينش اعضا بيرامون مسائل فردى و شخصيتى است (قربانى و

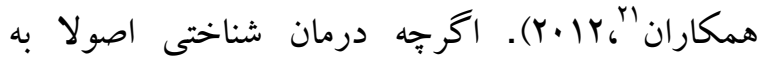
صورت يكك درمان فردى توسعه داده شده است، رويكردى است كه به صورت گروهى هم قابل كاربرد است. گروه درمانى شناختى - رفتارى) (GCBT) تواند به عنوان درمانى تعريف شود كه علاوه بر تكنيك هاى مشتر كك درمان شناختى - رفتارى بّبراى تغيير اختلال ها، ناساز گارى ها، و بد كار كردى عقايد، ادراكها، رفتارها و نكرش ها، از شيوه ى گروهى :يويا استفاده ميكند

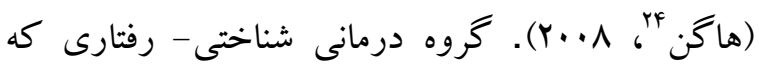
مستقيما از نوع فردى آن نشأت كرفته است، جانشين خوبى براى درمان انواع مختلفى از بيمارى هاى روانى

\footnotetext{
18. Miller, Willbourne \&Hettema

${ }_{19}$ Golpayegani, Khademi ashzari

${ }^{20}$. Group therapy

${ }^{21}$.Ghorbani, Mohamad khani, Sarami

${ }^{22}$.Group Cognitive Behavioral Therapy

23. cognitive behavioral therapy

24 .Hagen
} 
تركك اعتياد شهر تهران يكى از آنها به صورت قضاوتى انتخاب شد، با توجه به اينكه بهتر است تعداد افراد هر كروه در بُزوهش آزمايشى حداقل بين هشت تا دوازده

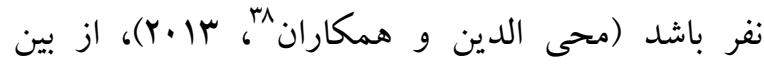
معتادان مراجعه كننده به آن مركز، يس از يكسان سازى آنها (بر حسب نوع ماده ى مصرفى، سن، تحصيلات،

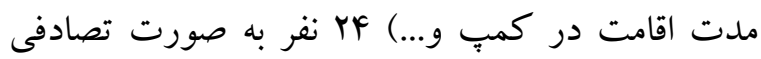
انتخاب شده و به طور تصادفى در دو گرووه گواه و

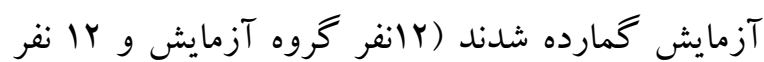

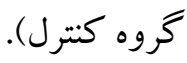
در طى دوره ى جلسات دو نفر از اعضاى گروه كنترل و دو نفر از اعضاى كروه آزمايش ريزش داشتند كه از هر كروه ده نفر باقى ماند. در اين يُزوهش از هر دو گروه (كروه آزمايش و گروه

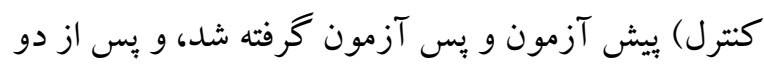

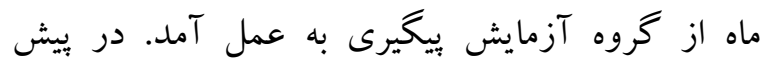
آزمون، بس آزمون و بيگيرى از برسشنامه اى به شرح زير استفاده شد.

يرسشنامه خو يشتن دارى: به منظور سنجش خويشتن دارى افراد معتاد از يرسشنامه خويشتن دارى (وين برگر و و

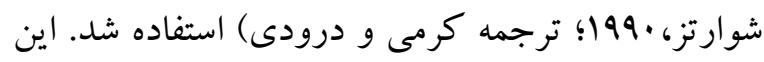
برسشنامه كه داراى ·r سوال است خويشتن دارى و مولفه هاى آن: سر كوب برخاشخرى، ملاحظه ي ديخران، كنترل تمايلات و مسئوليت بذيرى را اندازه گيرى ميكند.

(وين بركر و شوارتز، •991؛ ترجمه كرمى و درودى ) افراد شركت كننده در اين يثرهش سوءمصرف كنند كان مواد مخدر مراجعه كننده به مركز اقامتى ترك اعتياد نواى مهر و محبت بودند كه از لحاظ سن، مدت زمان

\footnotetext{
${ }^{38}$.Moheyedin, Sadeghi, Cheraghi, zarea
}

با توجه به كفته هاى بالا اعتياد معضلى است كه بسيارى از افراد هر جامعه را اسير خود نموده و ابعاد مختلف زندگى آنها را تحت تاثير خود قراد داده است. از جمله اين ابعاد كه موضوع اين تحقيق بوده خويشتن دارى افراد

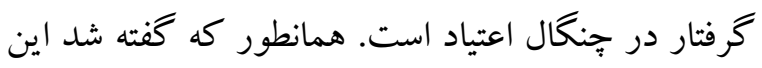
افراد از نظر خويشتن دارى در سطح يايينى قرار دارند و اين تحقيق درصدد يافتن روشى براى ارتقا اين بُعد از زندگى آنها مىباشد. مسئله اصلى اصلى در اين بئوهش اين است كه آيا گروه درمانى شناختى - رفتارى بر خويشتن دارى افراد سو, مصرف كننده مواد مخدر موثر است و اين درمان سبب بهبود خويشتن دارى اين افراد مى شود؟

\section{روش} اين بزوهش به صورت شبه آزمايشى و از نوع بيش آزمون، يس آزمون و يبيگيرى با گروه كنترل انجام شد. قبل از اجراى متغير مستقل، آزمودنى ها در هر گروه به به وسيله بيش آزمون مورد بررسى قرار گرفتند. به اين صورت كه بيست و جهار نفر از سوءمصرف كنند كان ساكن مركز اقامتى(كمبٍ) نواى مهر و محبت به صورت تصادفى انتخاب شدند و به صورت تصادفى در دو كروه آزمايش و كنترل قرار گرفتند. هر دو گروه به برسشنامه خويشتن دارى به عنوان بيش آزمون پِاسخ دادند. سپس كروه آزمايش، هشت جلسهى ·4 دقيقهاى، در گروه درمانى شناختى رفتارى شركت كردند. پِّ از اتمام جلسات از اعضاى هر دو گروه بـ آزمون گر فته شد و بعد از دو ماه نيز از گروه آزمايش بيگيرى به عمل آمد. جامعه آمارى يثزوهش تمام سوءمصرف كنند كان مواد مخدر مراجعه كننده به مراكز اقامتى(كمبٍ هاى) تركك اعتياد شهر تهران درسال سوبا مىباشد. روش نمونه كيرى تصادفى است. به اين ترتيب كه بين مراكز اقامتى 
روى آنها اجرا شد، بر روى گرووه كنترل هيجگگ نه درمانى

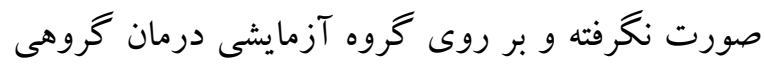
شناختى - رفتارى در هشت جلسه ى متوالى (هر هفته،

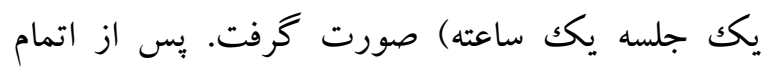
درمان، دو ماه بعد بيخيرى از طريق برسشنامه جى خويشتن

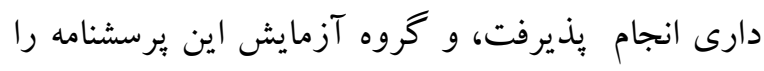
تكميل نمودند. جلسات گروه درمانى در جدول شماره ا آمده است:
اعتياد، ماده ى افيونى مصرفى و... يكسان سازى شدند (هر دو گروه در محدوده ى سنى لهتا ·F قرار داشتند، تحصيلات آنها شامل گستره ى زير دييلم تا ليسانس بود، همخى مرد بودند، حداقل به مدت شش ماه ساكن كمبِ بودند ، مدت مصرف آنها بين يكك تا شش سال بود و

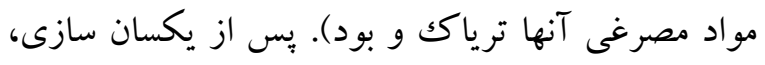
به طور تصادفى در دو گروه آزمايشى و كنترل قرار كرفته، برسشنامه ى خويشتن دارى وين بر خر و شوارتز بر

\section{جدول 1 شح جلسات درمان}

جلسه ى اول اجراى بيش آزمون، بحث و بررسى اهميت و هدف گروه درمانى، مشخص كردن زمان و مكان برگزارى و طول مدت جلسات،

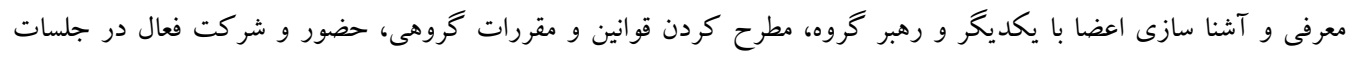
كروهى. استفاده از ييام هاى كلامى و غير كلامى، انعكاس و سوالات اكتشافى. از مراجعين خو استه شد شرح مختصرى از داستان

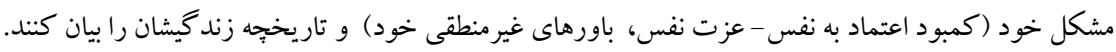

معرفى مدل شناختى - رفتارى (CBT)، فراهم كردن منطقى براى تكاليف خانكى، بالا بردن انگيزه(اميدوارى)، تقويت انخيزه و تعهد

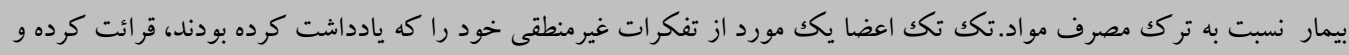
آن را تجزيه و تحليل كردند و اعضاى ديخر هم اظهار نظر نمودند. بررسى تكاليف، بررسى و توجه به دوسو گرايى بيمار در رابطه با تركك مصرف مو اد. شناسايى و مقابله با افكار مرتبط با مواد، شناسايى

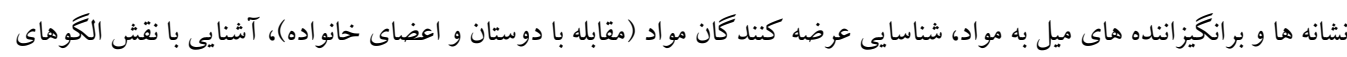

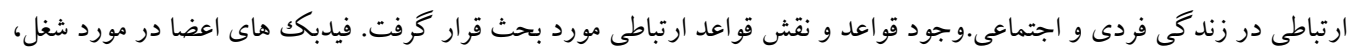

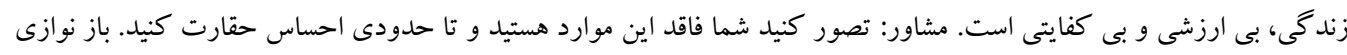
غير ارادى تصميمات دورانى كه اعضا مشكل دار بودند.

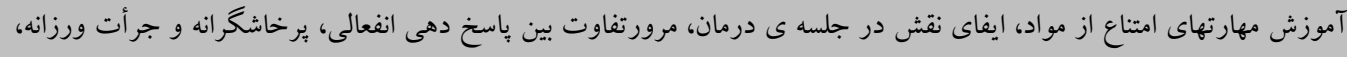

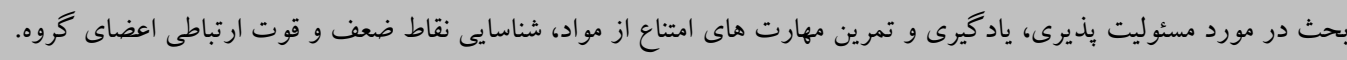

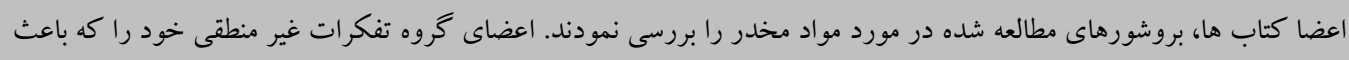

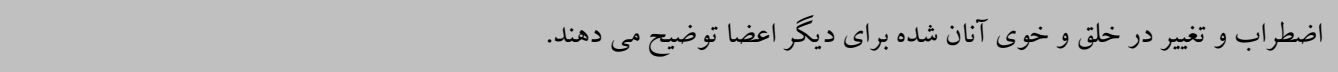

\section{جلسه ى دوم}

\section{جلسه ى سوم}

\section{جلسه جهارم}

بروسى تفكرات غير منطقى سطح توقع از ديخران، بحث در مورد شيوه هاى ارتباطى اعضا، تمرين عملى در گروه (كار با مدل (ABCD

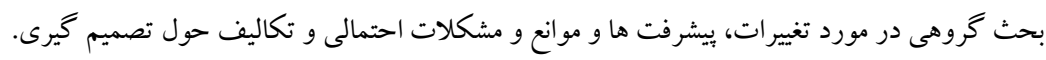

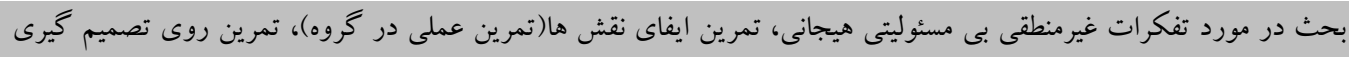

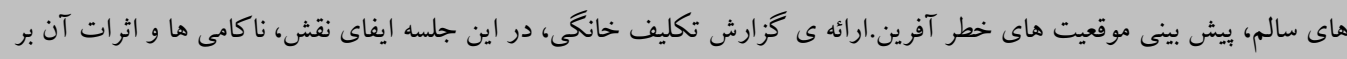
رفتار كنونى فرد بررسى و تجزيه و تحليل مى شود.

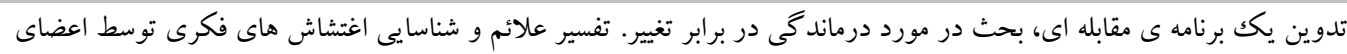

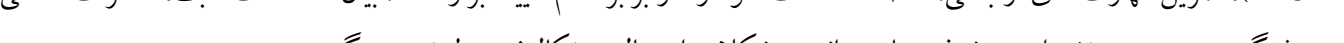

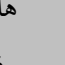

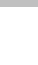

جلسه هفتم كروه. 


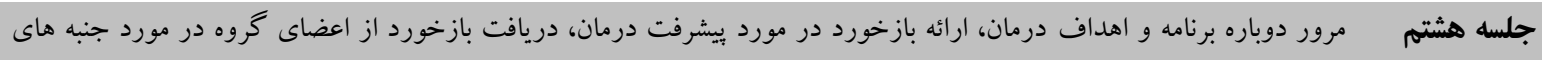

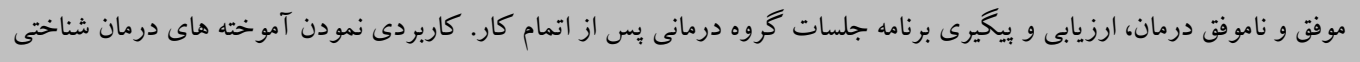

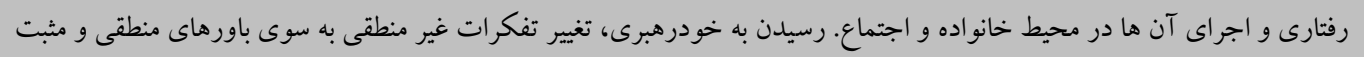

مستقل و خويشتن دارى بهعنوان متغير وابسته در نظر

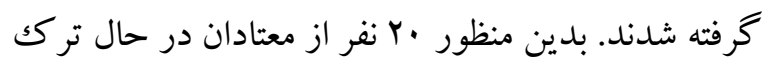

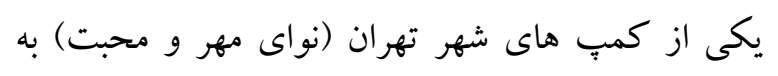

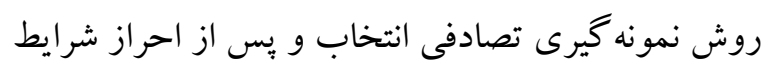

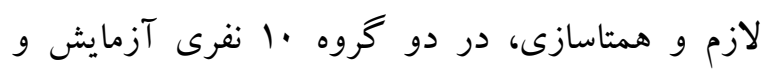

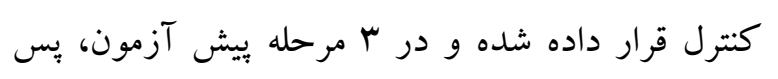
آزمون و بيگيرى بعد از دو ماه از نظر متغيرهاى وابسته مورد سنجش قرار گرفتند به منظور تجزيه و تحليل داده هاى بزّوهش، از روش هاى آمارى در دو سطح توصيفى و استنباطى استفاده شد. ويز گى هاى جمعيت شناختى معتادان در حال تركى كه استغاده در بيزوهش حاضر شركت داشتند در جدول r ب ارائه كرديده است.
در هشت جلسهى ذكر شده، مباحثى از درمان گرووهى

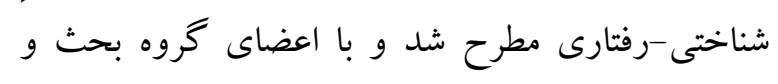
تبادل نظرهايى درباره ى مطالب ارائه شده انجام شد. به اعضاى گروه تكاليف خانگى داده شد و براى تجزيه و تحليل داده ها از نرم افزار SPSS و بخاطر اين كه اين يثوهش داراى گروه كنترل با بيش آزمون و يس آزمون

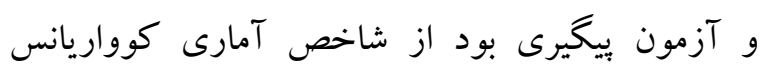
|ستفاده شد.

\section{يافتهها}

يزوهش حاضر با هدف بررسى اثربخشى گروه درمانى شناختى - رفتارى بر خويشتن دارى سوءمصرف كنتد كان مراجعه كننده به كمبٍ هاى ترك اعتياد شهر تهران صورت گرفت كه درمان شناختى رفتارى بهعنوان متغير

\begin{tabular}{|c|c|c|c|c|c|c|c|c|c|c|}
\hline \multicolumn{2}{|c|}{ وضعيت شغل } & \multicolumn{2}{|c|}{ تحصيلات } & \multicolumn{2}{|c|}{ وضعيت تأهل } & \multicolumn{2}{|c|}{ جنسيت } & ميانكين & \multirow[t]{2}{*}{ تعداد } & \multirow{2}{*}{ كروه ها } \\
\hline بيكار & شاغل & دييلم و بالاتر & زير دييلم & متاهل & مجرد & مونث & مذكر & سنى & & \\
\hline$\wedge$ & $r$ & r & $\wedge$ & 9 & r & - & 1. & $r F / Y \Delta$ & 1. & آزمايش \\
\hline$v$ & $r$ & 1 & 9 & $\Delta$ & $\Delta$ & - & 1. & $r r / 9$. & 1. & كنترل \\
\hline
\end{tabular}

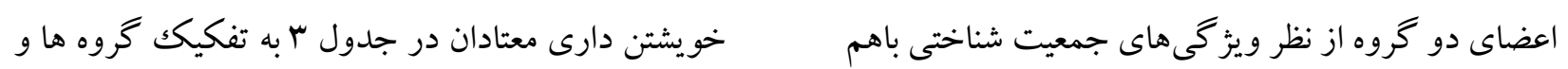
تناسب داشتند و همانطور كه در جدول ارائه شد، اكثرا مراحل نشان داده شده است. زير دييلم و بيكار بودند. ميانگين و انحراف معيار نمرات 


\begin{tabular}{|c|c|c|c|c|c|c|}
\hline$r / \Delta r$ & IV/A. & $\frac{\text { دارى }}{1 / v .}$ & 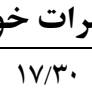 & ي و و انحر اف معون & \multirow{3}{*}{ سر كوب برخاشكرى } & \multirow{15}{*}{ خويشتن دارى } \\
\hline$r / q$. & IV/A. & $r / 11$ & $r r / v$. & يّ آزمون & & \\
\hline- & - & $r / 19$ & $r r / r$. & ييخيرى & & \\
\hline$r / \Delta \Lambda$ & $19 / r$. & r/Tr & $19 / 4$. & ييش آزمون & \multirow{3}{*}{ ملاحظه ديكر ان } & \\
\hline$r / v \wedge$ & $19 / r$. & $r / 4$ & $r F / r$. & يس آزمون & & \\
\hline- & - & $r / r r$ & $r F / l$. & ييخيرى & & \\
\hline$r / 11$ & $191 \cdot$. & $r / T V$ & $19 / 9$. & بيش آزمون & \multirow{3}{*}{ كنترل تمايلات } & \\
\hline$r / 4 G$ & $19 / r$. & $r / A r$ & $r \Delta / r$. & سֶ آزمون & & \\
\hline- & - & Y/AY & $r \Delta / 1$. & ييخيرى & & \\
\hline$r / M r$ & $19 / \cdot \cdot$ & Y/VY & $1 N / 9$. & يُيش آزمون & \multirow{3}{*}{ مسئوليت بذيرى } & \\
\hline$r / \mu$ & $19 / \cdot$. & $r / v q$ & $r \Delta / \Delta$. & يس آزمون & & \\
\hline- & - & $r / 90$ & $r \Delta / \Delta$. & ييخيرى & & \\
\hline $1 \cdot / 11$ & $V Y / l$. & $\Lambda / 4$ & $V Y / Y$. & يِيش آزمون & \multirow{3}{*}{ نمره كلى } & \\
\hline $11 / r$. & $V Y / F$ & $9 / \Gamma$. & $9 / / V$. & پֶ آزمون & & \\
\hline- & - & $9 / 1$. & $9 \Lambda / \cdot \cdot$ & ييخيرى & & \\
\hline
\end{tabular}

مراحل است. جهت تعيين اثربخشى گرووه درمانى

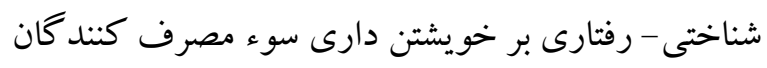
مو اد مراجعه كننده به مراكز اقامتى تركى اعتياد از آزمون تحليل كوواريانس استفاده شد و خلاصه ایى از نتايج تحليل كوواريانس نمرات بيش آزمون ، يّ آزمون و

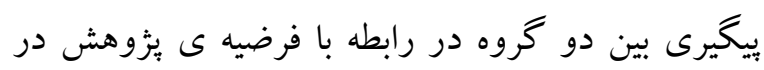
جداول زير گزارش شده است.

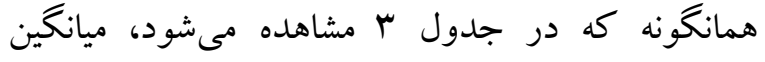
خويشتن دارى در گروه آزمايش در هريك از مراحل

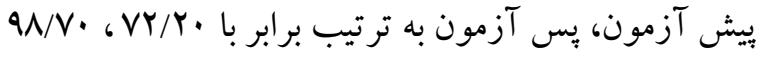
است كه نشان دهنده افزايش قابل ملاحظه نمرات بين مراحل است. در حالى كه ميانكين همين مقياس در گروه

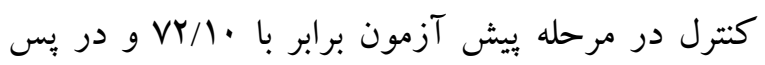

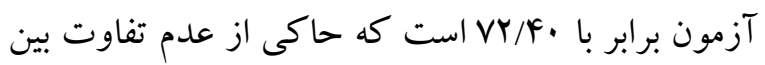

جدول † نتايج تحليل كوواريانس نمرات يس آزمون و بيعيرى متغير خويشتن دارى

\begin{tabular}{|c|c|c|c|c|c|c|c|c|c|}
\hline توان & اندازه & سطح معنى & فراوانى & مجذوراتكين & آزادى درجه & مجذمورات & منبع اثر & مراحل & متغير \\
\hline $1 / \cdot \cdot$ &.$/ 91$ & $\cdot / \cdots$ & $190 / F F$ & IVFN/A. & 1 & IVEA/A. & يِش آزمون & \multirow{2}{*}{ بֶس آزمون } & \multirow{4}{*}{ خويشتن دارى } \\
\hline $1 / \cdot$ & $\cdot / 90$ &.$/ \cdots$ & TYY/DD & MFr./GY & 1 & $M F r \cdot / g r$ & كروه & & \\
\hline $1 / \cdot \cdot$ &.$/ 94$ & $\cdot \cdots$ & $r M T / \Delta V$ & $10 \Delta F / 9 T$ & 1 & $10 \Delta \% / 9 r$ & بيش آزمون & \multirow{2}{*}{ ييخيرى } & \\
\hline $1 / \cdot$ &.$/ 99$ & $\cdot / \cdots$ & Far/rr & HYVG/AI & 1 & TYVG/AI & كروه & & \\
\hline
\end{tabular}


مواد مخدر مراجعه كننده به مراكز اقامتى (كمبِهاى)

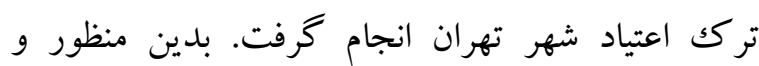
براساس اهداف تحقيق، فرضيه هايى تدوين و آزمون شد و داده هاى مربوط به آن در جداول مربوط و در قالب جداول مربوط ارائه شد.

\section{نتيجه كيرى}

شواهل يُوهشى اثربخشى جند نوع درمان رفتارى از جمله

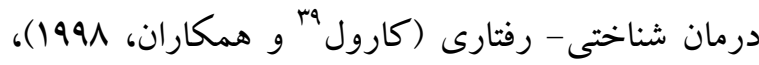

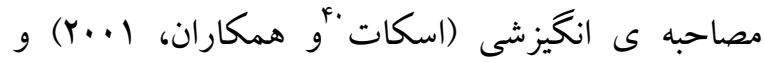

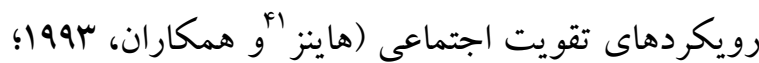
يرستون

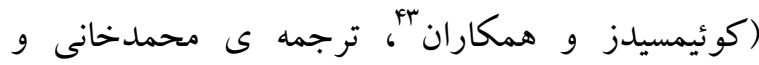

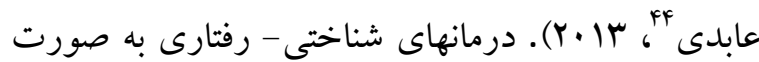
موفقيت آميزى در درمان اعتياد استفاده شده است (رينج

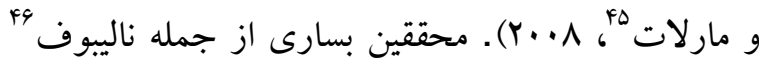
(Y..l) همكاران (ه · (Y) اثربخشى درمان شناختى - رفتارى را به عنوان يكى از راه هاى قابل بحث در كاهش نشانگان و وران درمان اختلالات روانى توام تاييد كرده اند (لطفى

$$
\text { كاشانى و همكاران }
$$

در گروه درمانى شناختى-رفتارى تغيير باورهاى غير منطقى آمـوزش داده مسى شـود و رفتارهاى مطلوب نيز تقويت مى شود. خود تنظيمى براى كنترل افكار و

39 .Karrol

${ }^{40}$. Skat

${ }^{41}$.Haynz

42 .Pereston

${ }^{43}$.Koimsids, Rinoldez, Dromound, Tarir

${ }^{44}$.Mohamadkhani, Abedi

${ }^{45}$.Rinch \& Marlat

46. Naliboof

${ }^{47}$.Bois

48 .Lakner

${ }^{49}$.Lotfi kashani, Behzadi, Yari
نتايج جدول F تحليل كوواريانس فوق نشان مىدهد كه كروه درمانى شناختى رفتارى در افزايش خويشتن دارى

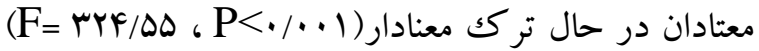
و ميزان اين تأثير هو درصد مى باشد. بنابراين، اين فرضيه مورد تأييد قرار مى گيرد. همجنين نتايج جدول تحليل كوواريانس نمرات بيخيرى حاكى از اين است كه گروه درمانى شناختى رفتارى در افزايش خويشتن دارى

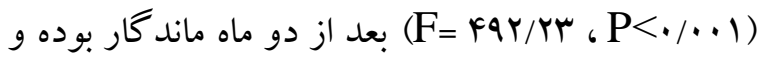
ميزان تأثير آن وه درصد مى باشد. اعتياد روح و جسم افراد را تسخير مى كند، بر مغز آنها اثرات سوء مى گذارد، بدترين آسيب ها را به اجتماع وارد مى كند، كانون خانواده ها را از هم مى پِاشد، به اقتصاد جامعه خسارت وارد مى كند و... از اين رو لازم به نظر مى رسد در اين زمينه و در راستاى بيشخيرى و درمان اين بيمارى صعب العلاج جاره اى انديشيد و كامى برداشت. كام هايى كه هرجند كوجّك اند اما شايد در اين راه مثمر ثمر باشند. بيمارى اعتياد كه آن را مى شود به معناى واقعى كلمه يكك بيمارى صعب العلاج ناميد تمام بيكره ى روحى و جسمى قربانى اش را تحت تاثير قرار داده و متلاشى مى كند و بند بند وجود او را نشانه مى گيرد، به حدى كه كيفيت زندگى بيمار ، قدرت تصميم گيرى، مسئوليت بذيرى، خود مختارى، خويشتن دارى و بسيارى از ويز گَى هاى روحى او تحت الشعاع قرار مى گيرد، و همين فراخير بودن اين بيمارى انجام اقدامات بيزوهشى (اعم از حيطه ى بيشخيرى و درمان) راضرورى مى سازد. يثزوهش حاضر به منظور بررسى اثر بخشى گروه درمانى شناختى -رفتارى بر خويشتن دارى سوء مصرف كنند كان 
خود كار آمدى در درمانجويان است (مرديور و همكاران، .$(Y \cdot) F$

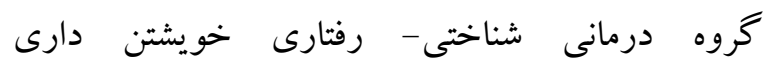
سوءمصرف كنندكان مواد مراجعه كننده به مراكز اقامتى تركك اعتياد را افزايش مى دهد، كه تاييد اين فرضيه همسو با بزوهش هاى زير است: فيلمور له و همكاران و و و (Y...V)

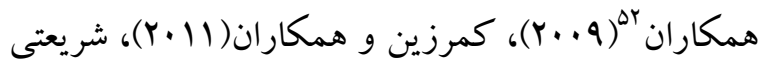

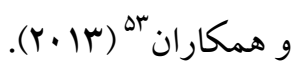

فرضيه ى اين بزظوهش تاييد شد. گروه آزمايش كه در جلسات گرووه درمانى شناختى رفتارى شركت كردند نسبت به گروه كنترل كه در اين جلسات شركت نكردند، از نظر خويشتن دارى و ابعاد آن بهبودى معنادارى را هم در بِ آزمون و هم در بيخيرى نشان دادند.

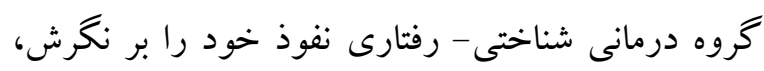
فكر، احساس و رفتار افراد اعمال مى كند و با بهبود توانايى فرد در زمينه هايى مانند: شناسايى افكار غيرمنطقى مرتبط با مواد، شناسايى نشانه ها و بر انگيز اننده هاى ميل به

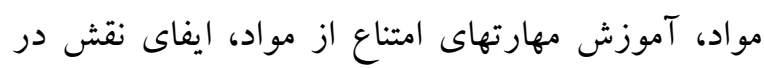
جلسه ى درمان، يادگيرى ياسخهاى جرات ورزانه و... توانايى فرد را بر خودكنترلى افزايش داده و وى را در برابر وسوسه ها مقاوم كرده و خويشتن دارى را افزايش مى دهد. بنابر اين با استناد به اين بثزوهش مى توان كفت

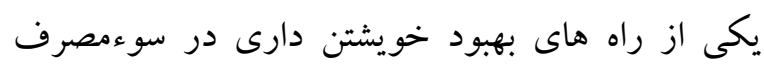
كنند گان مواد مخدر گرووه درمانى شناختى رفتارى است و از اين درمان مى توان در مراكز اقامتى تركك اعتياد،

${ }^{50}$. Filmoor

51 . Grant

${ }^{52}$.Jafari, Shahidi,Abedin

${ }^{53}$.Shariati, Izadi khah, Molavi, Salehi
احساسات به افراد آموزش داده شده و براى تغيير عقايد كنترل بيش از حد خود، آموزش برنامه ريزى روزانه كوتاه مدت و قابل دسترسى ارايه مى شـود. تغييـر

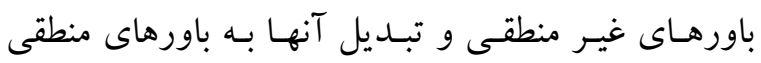
منجر به بيامدهاى عاطفى و رفتارى منطقى در فرد شده و به حفظ سـلامت روان فرد كمكك ميكند. به ايسن ترتيـب در گكروه درمـانى شـناختى رفتـارى دركك فـرد از خود، حس كفايت و مهارت هـاى مسأله گشايى،كسب درون استقلال، مهارت هـاى مقابله بـا موقعيتهاى خطر آفرين و فشار روانى و بسيارى از مهارت ها براى بهبـود

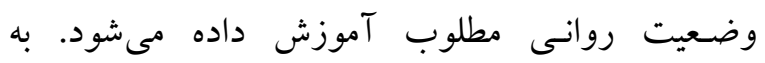
نظرميرسد رويكرد شناختى -رفتـارى از لحـاظ نظرى و عملى در زمينه عقايد مثبت و تدابير كنترل در بيماران

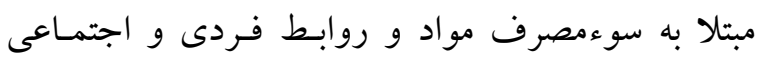

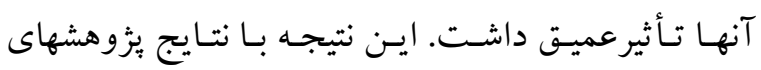
يور شريفى و همكاران (111) و صـولتى دهكردى و

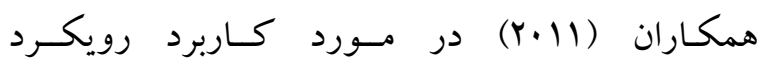
شـناختى -رفتـارى همـسو اســت اين نتايج با يافته هاى به دست آمده از تحقيق هاى ساير

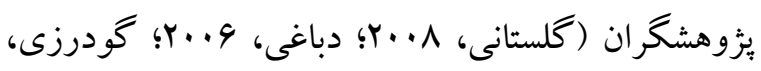

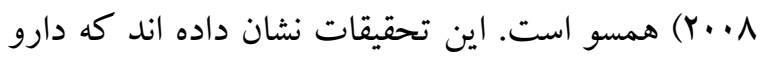
درمانى به تنهايى قادر به درمان كامل وابستكى افراد به إنه مواد نبوده و مداخلات روانشناختى بخش مهمى از درمان

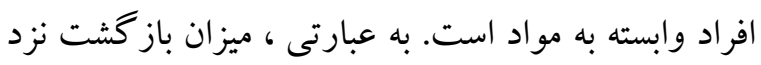

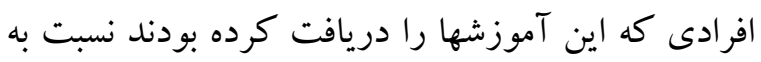

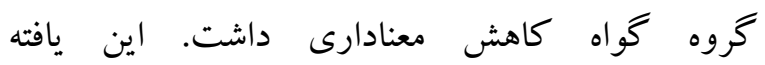
نشانكراثربخش بودن مداخله هاى روان درمانى مبتنى بر

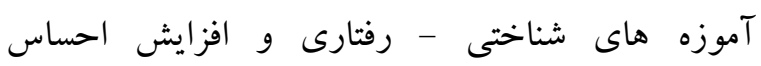


provocative stimuli among Clean persons referring to addiction treatment centers in East Azarbaijan province. Master's Degree in Educational Psychology, Islamic Azad University, Central Tehran Branch, Faculty of Psychology and Social Sciences.

Golpaygani, F; Khademi Azhezari ,M . (2012). The relationship between commitment to school, attitudes toward drugs and its consumption among students. Quarterly journal of drug addiction. 6(22).

Hagen R. (2008) . Group and individual based cognitive behavioral therapy for server psychiatric disorders. Thesis for the degree philosophiae doctor, Norwegian University of Science and Technology Management Department of Psychology.

Haidarzadegan , A; Kazemi , Y; Sanaatizadeh , F. (2010). Investigating the relationship between continence creativity and leadership styles of educational managers. Master's Thesis in Educational Management, Sistan Baluchistan University.

I L Lemos, C N Abreu, E B Sougey. (2014) . Intemet and video game addictions: a cognitive behavioral approach. Dependencia de Intemet e de jogos eletronicos: um enfoque cognitivocomportamental. 68, 402-411.

Jafari, M; Shahidi, Sh; Abedin , A (2002). Comparing the Effectiveness of Cognitive-Behavioral Therapy and Trans-theoretical Model on Improing abstinence self-efficacy in substance dependent Adolescents. Journal of Research in Behavioral Sciences 7, (1).

Kamarzin , H; Zare; H; BrookiMilan; H.(2011). The effectiveness of cognitive-behavioral therapy on self-efficacy and the improvement of addiction symptoms in drug-dependent patients. (6) (22).

Kazemi, Y; Mehdinezhad, V; Jamali , R .(2011). The Relationship between Emotional Intelligence, continence and Organizational Commitment of Managers. Management and Development Process, 78

Keshavarz, M; Ghamarani, A; Bagherian, M; Rezaei, AM .(2014). The Role of Preceding the

$$
\begin{aligned}
& \text { كلينيك هاى درمان دارويى اعتياد، گروه هاى معتادان } \\
& \text { كمنام و... استفاده كرد. } \\
& \text { بيشنهاد مى شود در تحقيق هاى آينده نمونه ى بزركتر } \\
& \text { انتخاب شود و تاثير جنسيت بر اين درمان نيز مورد بررسى }
\end{aligned}
$$

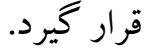

$$
\begin{aligned}
& \text { سياسگز ارى } \\
& \text { از آقاى دكتر فرامرز سهرابى و آقاى دكتر احمد برجعلى سيى } \\
& \text { اعضاى هيئت علمى دانشگاه علامه طباطبايى، و آقاى } \\
& \text { احمد جراغى زارع آبادى سريرست مركز اقامتى ترك } \\
& \text { اعتياد نواى مهر و محبت به علت همكارى در انجام اين } \\
& \text { يزوهش سياسگز ارى مى شود. }
\end{aligned}
$$

\section{References}

Ameli , T; Abolma'ali , Kh ; Mirzaei, B. (2012). Comparison of conflict resolution and quality of life of opiate addicts with substance abuse addicts, Quarterly Journal of Research on Addiction, 6(24), 68-55.

Bemard P Range, G Alan Marlatt (2008 ). cognitive behavioral therapy for alcohol and drug use disorders. Rev Bras Psiqiuater. 30(2),588-595.

D L Scker, RG Brown.( 2005) . Cognitive behavioral therpy (CBT) for carer of patients with parkinsons disease: a preliminary randomized controlled trial. J Neurosourg Psychiat. 76, 491-49atment of Addiction, Joumal of Behavioral Sciences Research, 12 (1), 153144.

Dastjani Farahani, A ; Rahmani, M A; Tizdast, T. (2013). The Effectiveness of CognitiveBehavioral Group Therapy on Unreasonable Beliefs and Quality of Life in AmphetamineAffiliated Patients. Quarterly Joumal of Research on Addiction. 7 (28).

Goli, S; Emamipor, S; Javanmard, Gh .(2012). The effect of life skills training on the reduction of temptation and bias in attention to opioid 
هـ اثربخشى كروه درمانى شناختى -رفتارى بر خو يشتن دارى سوءمصرف كنند كان مواد مخدر مر اجعه كننده به مر اكز اقامتى تركى اعتياد شهر تهران

Spiritual Orientation of Addicts and their Psychosocial Survival in the Treatment of Addiction, Joumal of Behavioral Sciences Research, 12(1), 144-153.

Lotfi Kashani, F; Behzadi , S; Yari , M. (2012). Effectiveness of cognitive-behavioral group therapy on quality of life and anxiety in imitable bowel patients. Joumal of Medical Sience Islamic Azad University, 22 (4), 306301.

Manzari , F; Rajaepour, S; Abedi, A. (2012). Investigating the relationship between continence and psychological empowerment among managers, deputies and teachers of Farid city, Master's thesis of educational management, Isfahan University, Faculty of Psychology and Educational Sciences.

Mardpor, A; Najafi, M; Amiri, F. (2014). The effectiveness of the prevention of recurrence based on mindfulness in preventing recurrence, self-control and self-control in opiate dependent people. Quarterly Joumal of Research on Addiction,8 (32).

Mohammad Khani, Sh; Sarrami, Gh .(2012). Comparison of the effectiveness of cognitive behavioral group therapy and methadone maintenance therapy in changing the beliefs associated with the substance and anticipating recurrence . Quarterly Joumal of Research on Addiction,. , 6(22).

Momeni , F; Mushtaq, N; Pour Shahbaz , A. (2013). Effectiveness of cognitive-behavioral group therapy on improving the quality of life of opiate addicts under methadone maintenance treatment, Quarterly Joumal of Research on Addiction, 7 (27).

Narimani , M ; Habibi , Y; Rajabi, S .(2012). Comparison of emotional intelligence and quality of life in addicted and non-addicted men. Quarterly Journal of Research on Addiction, 5(19), 38-21.

Pim C, Filip S, Emst B, Steven D Hollon Gerhard Andersson. (2010). Efficacy of cognitivebehavioural therapy and other psychological treatments for adult depression. meta-analytic study of publication bias. The British journal of Psychiatry, 196, 173-178

Quimicides , Ch; Reynolds , M; Drummond, Ch; Tarier, N. Cognitive Behavioral Addiction. Translation of Mohammadkhani, Abedi (2012). Tehran. Danzheh.

Shariati , M E; Izadikhah , Z; Molavi , H; Salehi, M .(2013). Comparison of the effectiveness of Cognitive-behavioral therapy group with treatment based on improving quality of life on self-efficacy of addicted people. Joumal of Research in Behavioral Sciences, 11 (4), 288279.

Soares T, Camargo J, Pizzinato A. (2013) . Effectivenss of Groug Cognitive Behavioral Therapies for Panic Disorder. Revista Brasileira de Terapia Comportamentale Cognitiva, 1,50-82.

Tabatabaee Chahar, M; Ebrahimi sani , E; Mortazavi, H .(2012). The Effectiveness of CognitiveBehavioral Psychotherapy on Changing of Irrational Beliefs in Male Addicts. North Khorasan University of Medical Sciences, 4 (2), 430-419.

Tajery, B; Ahadi, H; Jomehri, F .(2011). The study of the effect of cognitive-behavioral therapy on avoidance, temptation, relapse and change in attitude of glass addicts. Quarterly Joumal of Clinical Psychology, 2(7).

Walter SA, pickard H. (1997) . What is addiction? Forthcoming in the oxford handbook of philiosophy of psychiatry(oup) B.Fulford , R.Gipps , J.Sadler ,eds.

Wehmeyer M, Schwarts M (1998). The Relationship Between Self-Determination and Quality of Life For Adult With Mental Retardation. Educational and Training in Mental Retardation and develope Mental,33(1),3-12.

Zadhoosh, S; Taher Neshat Dost, H; Kalantari, M; Rasoulzadeh Tabatabaei; S K .(2011). Comparison of the Efficacy of CognitiveBehavioral Group Therapy with Religious Advice and Classic Cognitive-Behavioral Group Therapy on the Quality of Marital Relationship of Women. Quarterly Joumal of Family Research, 7 (25). 55-68. 